\title{
FILMES ULTRAFINOS DE ÉSTERES DE CELULOSE: PREPARO, CARACTERIZAÇÃo E IMOBILIZAÇÃo DE PROTEÍNAS ${ }^{*}$
}

\author{
Jorge Amim Jr. e Denise F. S. Petri* \\ Instituto de Química, Universidade de São Paulo, Av. Prof. Lineu Prestes, 748, 05508-900 São Paulo - SP, Brasil \\ Francisco C. B. Maia e Paulo B. Miranda \\ Instituto de Física, Universidade de São Paulo, Av. Trabalhador São Carlense, 400, 13566-590 São Carlos - SP, Brasil
}

Recebido em 8/6/10; aceito em 29/9/10; publicado na web em 25/10/10

\begin{abstract}
ULTRATHIN CELLULOSE ESTER FILMS: PREPARATION, CHARACTERIZATION AND PROTEIN IMMOBILIZATION. In this study cellulose acetate butyrate $(\mathrm{CAB})$ and carboxymehtylcellulose acetate butyrate (CMCAB) films adsorbed onto silicon wafers were characterized by means of ellipsometry, atomic force microscopy (AFM), sum frequency generation spectroscopy (SFG) and contact angle measurements. The adsorption behavior of lysozyme (LIS) or bovine serum albumin (BSA) onto CAB and CMCAB films was investigated. The amounts of adsorbed LIS or BSA onto CMCAB films were more pronounced than those onto CAB films due to the presence of carboxymethyl group in the CMCAB structure. Besides, the adsorption of BSA molecules on CMCAB films was more favored than that of LIS molecules. Antimicrobial effect of LIS bound to CAB or CMCAB layers was evaluated using Micrococcus luteus as substrate.
\end{abstract}

Keywords: cellulose ester; protein adsorption; film characterization.

\section{INTRODUÇÃO}

A formação de filmes finos de polissacarídeos sobre superfícies sólidas tem uma importância significativa, devido principalmente à capacidade de aplicação desses filmes na imobilização de biomoléculas, ${ }^{1,2}$ o que fornece condições para o desenvolvimento de biossensores. ${ }^{3}$ Para esta finalidade, superfícies de polissacarídeos têm se destacado em relação aos polímeros sintéticos por serem biocompatíveis e provenientes de fontes renováveis. ${ }^{4}$

Ésteres de celulose são polímeros derivados da celulose com maior número de aplicações tecnológicas Estes derivados de celulose são largamente utilizados em formulações de tintas e revestimentos à base de solventes orgânicos para melhorar as propriedades de fluxo (viscosidade), a capacidade de polimento, estabilidade à radiação UV, resistência ao amarelecimento, resistência a fissuras no filme e dispersão dos pigmentos. ${ }^{5}$ Os ésteres de celulose mais utilizados em revestimentos são acetato de celulose (CA), propionato acetato de celulose (CAP) e butirato acetato de celulose (CAB). ${ }^{5} \mathrm{Na}$ formulação de revestimentos metálicos para a indústria automotiva, a presença de CAB ajuda na orientação paralela das partículas metálicas. ${ }^{5}$ No segmento de tintas decorativas $\mathrm{CAB}$ tem sido usado como compatibilizante e agente promotor de retenção de cor, flexibilidade e resistência à umidade. ${ }^{5}$

$\mathrm{O}$ acetato butirato carboximetil celulose $(\mathrm{CMCAB})$ é um éster de celulose insolúvel em água, mas solúvel em solventes como acetato de etila, metanol e acetona, que reúne duas características em um só material: o caráter hidrofílico dos grupos acetato e carboximetil e o caráter hidrofóbico devido ao radical butirato. ${ }^{5,6} \mathrm{CMCAB}$ pode ser obtido a partir da esterificação de carboxialquil celulose. ${ }^{5} \mathrm{~A}$ diferença na estrutura química entre $\mathrm{CMCAB}$ e o éster de celulose $\mathrm{CAB}$ é a presença do grupo carboximetil $\left(\mathrm{CH}_{2} \mathrm{COOH}\right)$, como mostrado na Figura 1. As patentes encontradas sobre $\mathrm{CMCAB}$ focam aplicações tecnológicas, tais como a aplicação em pinturas automotivas, ${ }^{7}$ na dispersão de materiais hidrofóbicos em solução aquosa, além de seu uso como

*e-mail: dfsp@iq.usp.br

"Artigo respeitosamente dedicado ao querido Prof. Hans Viertler aditivo em tintas, dando mais durabilidade à impressão da mesma. ${ }^{8,9}$ Mais recentemente, $\mathrm{CMCAB}$ está sendo usado como matriz para formulações farmacêuticas. ${ }^{6}$ Neste trabalho, as propriedades superficiais de filmes ultrafinos de $\mathrm{CAB}$ e $\mathrm{CMCAB}$ foram investigadas através de elipsometria, microscopia de força atômica (AFM), medidas de ângulo de contato e espectroscopia vibracional por geração de soma de frequências (SFG). Na literatura nota-se a ausência de estudos sobre a aplicação de filmes finos de CMCAB como substratos para adsorção de biomoléculas. Por esta razão, este trabalho explorou a aplicação de filmes finos de CMCAB como suporte para imobilização de proteínas. Foram escolhidas duas proteínas com características diferenciadas para o estudo de imobilização de biomoléculas: a lisozima (LIS), que é uma enzima com função bactericida, ${ }^{10}$ e a albumina de soro bovino (BSA), que é uma proteína globular com larga aplicação no desenvolvimento de kits de diagnósticos. ${ }^{11}$<smiles>[R]CC1OC(OC)C([R])C([R])C1OC</smiles>

Figura 1. Representação da estrutura química do acetato butirato carboximetil celulose (CMCAB), onde $\mathrm{R}^{2}, \mathrm{R}^{3}$ e $\mathrm{R}^{6}: \mathrm{H}, \mathrm{COCH}_{2} \mathrm{CH}_{2} \mathrm{CH}_{3}, \mathrm{CH}_{2} \mathrm{COOH}$ e $\mathrm{COCH}_{3}$ e do acetato butirato celulose (CAB) onde $\mathrm{R}^{2}, \mathrm{R}^{3}$ e $\mathrm{R}^{6}: \mathrm{H}$, CO$\mathrm{CH}_{2} \mathrm{CH}_{2} \mathrm{CH}_{3}$ e $\mathrm{COCH}_{3}$

\section{PARTE EXPERIMENTAL}

\section{Materiais}

Lâminas de silício $\left(\mathrm{Si} / \mathrm{SiO}_{2}\right)$ adquiridas da Silicon Quest (Califórnia, EUA) foram usadas como substrato nas dimensões de $1 \mathrm{x} 1 \mathrm{~cm}$ para experimentos de obtenção de filmes ultrafinos. Foram utilizados água destilada e acetato de etila (grau analítico) como solventes. Cloreto de sódio foi adquirido da Nuclear (São Paulo, Brasil). Os polímeros acetato butirato celulose $(\mathrm{CAB})$ e acetato butirato carbo- 
ximetil celulose (CMCAB) foram gentilmente cedidos pela Eastman do Brasil (Tabela 1). LIS (L7651, Sigma, MM = $14.3 \mathrm{kDa}$ ) de clara de ovo e BSA (A2153, Sigma, MM = 66 kDa) foram utilizadas sem purificação prévia.

Tabela 1. Características do acetato butirato celulose (CAB) e acetato butirato de carboximetilcelulose (CMCAB): massa molar média numérica $\left(M_{n}\right)$, temperatura de transição vítrea $\left(\mathrm{T}_{\mathrm{g}}\right)$, temperatura de fusão $\left(\mathrm{T}_{\mathrm{m}}\right)$, grau de esterificação para o acetato $\left(\mathrm{DS}_{\mathrm{AC}}\right)$, butirato $\left(\mathrm{DS}_{\mathrm{BU}}\right)$, carboximetil $\left(\mathrm{DS}_{\mathrm{CM}}\right)$ e hidroxila $(\mathrm{OH})$

\begin{tabular}{|c|c|c|c|c|c|c|c|c|}
\hline Polímero & Código & $\begin{array}{c}M_{n} \\
(\mathrm{~g} / \mathrm{mol})\end{array}$ & $\begin{array}{c}\mathrm{T}_{\mathrm{g}} \\
\left({ }^{\circ} \mathrm{C}\right)\end{array}$ & $\begin{array}{c}\mathrm{T}_{\mathrm{m}} \\
\left({ }^{\circ} \mathrm{C}\right)\end{array}$ & $\mathrm{DS}_{\mathrm{AC}}$ & $\mathrm{DS}_{\mathrm{BU}}$ & $\mathrm{DS}_{\mathrm{CM}}$ & $\mathrm{OH}$ \\
\hline $\begin{array}{l}\text { Acetato butirato } \\
\text { carboximetil } \\
\text { celulose }\end{array}$ & $\begin{array}{c}\text { CMCAB } \\
641-0,2\end{array}$ & 20000 & 135 & $145-160$ & 0,44 & 1,64 & 0,33 & 0,59 \\
\hline $\begin{array}{l}\text { Acetato butirato } \\
\text { celulose }\end{array}$ & $\begin{array}{c}\text { CAB } \\
381\end{array}$ & 20000 & 125 & 160 & 0,95 & 1,65 & - & 0,4 \\
\hline
\end{tabular}

Dados fornecidos pelo fabricante (Eastman).

\section{Métodos}

\section{Preparação dos filmes ultrafinos finos dos polímeros $C A B e$ CMCAB}

Primeiramente as lâminas de $\mathrm{Si} / \mathrm{SiO}_{2}$ foram limpas, imergindo-as em uma mistura oxidativa contendo $\mathrm{H}_{2} \mathrm{O}_{2}, \mathrm{NH}_{4} \mathrm{OH}$ e $\mathrm{H}_{2} \mathrm{O}$, na proporção de 1:1:4 em volume, à temperatura de $75^{\circ} \mathrm{C}$, durante $20 \mathrm{~min}$. Depois desse período, retirou-se as lâminas da mistura, lavou-se em água destilada e secou-se com jatos de nitrogênio. Em seguida, as lâminas de $\mathrm{Si} / \mathrm{SiO}_{2}$ foram colocadas em contato com soluções de $\mathrm{CAB}$ e CMCAB preparadas em acetato de etila na concentração de 1,5 g/L. Após $21 \mathrm{~h}$ de adsorção, os substratos foram lavados com acetato de etila e secos com jatos de $\mathrm{N}_{2}$. Os experimentos de dessorção foram realizados deixando-se os substratos adsorvidos com os polímeros em contato com o solvente puro por $21 \mathrm{~h}$. Os experimentos de adsorção e dessorção foram realizados a $25 \pm 1{ }^{\circ} \mathrm{C}$.

Adsorção de proteínas sobre os filmes ultrafinos de CAB e CMCAB

As lâminas de $\mathrm{Si} / \mathrm{SiO}_{2}$ cobertas com os filmes finos de ésteres de celulose foram imersas em soluções aquosas das proteínas LIS ou BSA na concentração de $1 \mathrm{~g} / \mathrm{L}$ a $25 \pm 1{ }^{\circ} \mathrm{C}$ e $\mathrm{pH}=6,4 \pm 0,1$, durante $21 \mathrm{~h}$. Este período garante que o equilíbrio de adsorção seja atingido. O efeito da força iônica sobre a adsorção da LIS ou BSA foi investigado preparando-se soluções dessas proteínas em 0,01 e $0,1 \mathrm{~mol} / \mathrm{L}$ de $\mathrm{NaCl}$. Após o período de adsorção, os substratos foram removidos das soluções, lavados com água destilada e secos com jatos de $\mathrm{N}_{2}$. Os experimentos de dessorção foram realizados deixando-se os substratos recobertos com proteínas em contato com água pura ou com solução de $\mathrm{NaCl}$ na concentração de 0,01 ou $0,1 \mathrm{~mol} / \mathrm{L}$ por $21 \mathrm{~h}$.

\section{Elipsometria}

A elipsometria consiste em medir a mudança do estado de polarização da luz após a reflexão de um feixe de luz, a partir de uma superfície isotrópica refletora. ${ }^{12}$ As medidas de elipsometria foram realizadas utilizando o elipsômetro DRE - ELX02 (Ratzeburg, Alemanha) equipado com um laser $\mathrm{He}-\mathrm{Ne}(\lambda=632,8 \mathrm{~nm})$ ajustado em um ângulo de incidência de $70,0^{\circ}$ que cobre uma área superficial de aproximadamente $3 \mathrm{~mm}^{2}$ da amostra em análise, em temperatura ambiente. Para a interpretação dos dados, utilizou-se um modelo de multicamadas formado pelo substrato, uma camada desconhecida e o meio externo. A espessura $\left(d_{x}\right)$ e o índice de refração $\left(n_{x}\right)$ da camada desconhecida podem ser calculados através das variações de fase $(\Delta)$ e amplitude $(\Psi)$ relativas à radiação incidente, das relações de Drude e Fresnel, da equação fundamental da elipsometria (Equação 1) e de cálculos iterativos através de matrizes de Jones: ${ }^{13}$

$$
\mathrm{e}^{\mathrm{i} \Delta} \tan \Psi=\mathrm{R}_{\mathrm{p}} / \mathrm{R}_{\mathrm{s}}=\mathrm{f}\left(\mathrm{n}_{\mathrm{k}}, \mathrm{d}_{\mathrm{k}}, \lambda, \phi\right)
$$

onde $\mathrm{R}_{\mathrm{p}}$ e $\mathrm{R}_{\mathrm{s}}$ são os coeficientes de reflexão total para as ondas paralela e perpendicular e dependem do ângulo de incidência $\phi$, do comprimento de onda $\lambda$ da radiação, do índice de refração e da espessura de cada camada do modelo, $\mathrm{n}_{\mathrm{k}}, \mathrm{d}_{\mathrm{k}}$. A partir dos ângulos elipsométricos $\Delta$ e $\Psi$ e de um modelo de multicamadas formado pelo silício, o óxido de silício, a camada de $\mathrm{CMCAB}$ ou $\mathrm{CAB}$ e ar é possível determinar somente a espessura da camada de CMCAB ou CAB. Inicialmente, a espessura da camada de $\mathrm{SiO}_{2}$ das lâminas foi determinada em ar, considerando o índice de refração para o Si como $\tilde{n}=3,88-i 0,018^{14}$ e sua espessura como infinita. Para o meio externo (ar) o índice de refração foi considerado como 1,00. Como a camada de $\mathrm{SiO}_{2}$ nativa é muito fina utiliza-se $n=1,462^{14}$ para calcular sua espessura, que é de aproximadamente 1,9 $\pm 0,2$ nm. A espessura da camada de CAB e CMCAB foi calculada considerando o índice de refração nominal de $n=1,48$ para ambos os polissacarídeos. ${ }^{15} \mathrm{~A}$ espessura da camada proteica foi calculada considerando o índice de refração nominal de $n=1,52$ para LIS e BSA, este valor é típico de proteínas. ${ }^{16}$ As incertezas experimentais associadas à técnica de elipsometria envolvem a leitura de ângulos de dois polarizadores e do ângulo de incidência do laser, que quando propagadas no cálculo da espessura e de índice de refração geram incertezas da ordem de $10 \%$ do valor médio. As medidas elipsométricas foram feitas em triplicata para cada polissacarídeo antes e após a imobilização de LIS ou BSA. Os valores médios de espessura com os respectivos desvios padrão apresentados neste trabalho contemplam as incertezas da técnica e as replicatas.

A quantidade de proteína adsorvida, $\Gamma\left(\mathrm{mg} / \mathrm{m}^{2}\right)$, pode ser calculada através da Equação 2: ${ }^{17}$

$$
\Gamma=\mathrm{d} . \rho
$$

onde $d$ é a espessura da camada de proteína adsorvida e $\rho$ é densidade das proteínas e/ou polissacarídeos. Neste caso, para as proteínas ${ }^{17}$ $\rho=1,37 \mathrm{~g} / \mathrm{cm}^{3}$ e para os ésteres de celulose $\rho=1,21 \mathrm{~g} / \mathrm{cm}^{3}$ (dado fornecido pelo fabricante).

\section{Microscopia de força atômica (AFM)}

A caracterização da superfície dos filmes do CAB e CMCAB e das proteínas imobilizadas sobre o filme desses polímeros foi realizada através de imagens obtidas por medidas de AFM, utilizando o equipamento Molecular Imaging Pico LE Microscope. As imagens foram obtidas no modo de contato intermitente, a temperatura ambiente, usando cantilevers de silício com frequência de ressonância próxima de $300 \mathrm{kHz}$ e constante de mola nominal de $42 \mathrm{~N} / \mathrm{m}$. As imagens apresentadas neste trabalho se referem a áreas de varredura de $(1$ x $1 \mu \mathrm{m})$ com resolução de 512 x 512 pixels. Os valores de rugosidade média (RMS) foram obtidos pelo software PicoPlus.

\section{Medidas de ângulo de contato}

As medidas de ângulo de contato em graus foram obtidas pelo método da gota séssil, ${ }^{18}$ numa montagem construída no laboratório (Figura 1S, material suplementar). Gotas de água destilada de $8 \mathrm{e}$ $4 \mu \mathrm{L}$ foram usadas para os ângulos de avanço $\left(\theta_{\mathrm{A}}\right)$ e recesso $\left(\theta_{\mathrm{R}}\right)$, respectivamente. A histerese no ângulo de contato $\left(\Delta \theta=\theta_{A}-\theta_{R}\right)$ nos dá uma indicação da rugosidade da superfície e da heterogeneidade química da superfície. ${ }^{18}$ As medidas foram feitas em triplicata para CAB e CMCAB antes e após a adsorção das proteínas. 
Espectroscopia vibracional por geração de soma de frequências (SFG)

A espectroscopia SFG é uma técnica de ótica não linear baseada na interação de dois fótons na superfície. Na espectroscopia SFG, os fótons de soma de frequências $\left(\omega_{\mathrm{SFG}}=\omega_{\mathrm{IR}}+\omega_{\mathrm{VIS}}\right)$ são gerados pela interação de dois feixes de laser pulsado, um feixe infravermelho sintonizável de frequência $\omega_{\text {IR }}$ e um feixe visível de frequência fixa $\omega_{\mathrm{VIS}}$. Medindo-se o sinal de SFG em função da frequência do feixe de infravermelho obtém-se um espectro vibracional das moléculas na interface, sem contribuição das moléculas no volume do material. ${ }^{19} \mathrm{~A}$ aplicação desta técnica permite a investigação de espectros vibracionais de polímeros presentes em uma determinada interface, ${ }^{20,21}$ bem como obter informações sobre sua orientação média.

Filmes de $\mathrm{CAB}$ e $\mathrm{CMCAB}$ adsorvidos a partir de solução em acetato de etila na concentração de $1,5 \mathrm{~g} / \mathrm{L}$ sobre quartzo foram utilizados nos experimentos de SFG. Os espectros de SFG dos filmes de CAB e CMCAB secos foram obtidos em um espectrômetro (Ekspla) equipado com um laser pulsado de $\mathrm{Nd}^{+3}$ :YAG (taxa de repetição 20 $\mathrm{Hz}$, duração do pulso 28 ps, comprimento de onda $1064 \mathrm{~nm}$ ) que excita uma unidade geradora de harmônicos. Essa unidade produz feixes de $2^{\circ}$ harmônico a $\lambda=532 \mathrm{~nm}$ (visível) e de $3^{\circ}$ harmônico a $\lambda=355 \mathrm{~nm}$ (UV), além de permitir um sinal de saída no comprimento de onda $\lambda$ $=1064 \mathrm{~nm}$ (fundamental). Este fundamental e o $3^{\circ}$ harmônico excitam um oscilador/amplificador paramétrico óptico que será responsável pela geração do feixe infravermelho (IR) sintonizável, que incidirá sobre a amostra juntamente com o feixe no visível $(\lambda=532 \mathrm{~nm})$. Os ângulos de incidência e energias por pulso são de $55^{\circ} \mathrm{e} \sim 200 \mathrm{~mJ}$ para o feixe na região do IR, e $61^{\circ}$ e $\sim 900 \mathrm{~mJ}$ para o feixe visível; os feixes iluminam uma região na amostra de $\sim 0,5 \mathrm{~mm}$ de diâmetro. $\mathrm{O}$ sinal SFG é coletado por um conjunto monocromador/fotomultiplicadora em função da frequência do feixe do infravermelho e cada ponto do espectro é uma média do sinal obtido para 100 pulsos do laser. Neste estudo, os dados foram obtidos na região do IR entre 1600 e $1800 \mathrm{~cm}^{-1}$ e entre 2800 e $3000 \mathrm{~cm}^{-1}$. O sinal SFG pode ser obtido nas combinações de polarização ppp, sps e ssp, onde "s" e "p" indicam que a luz está polarizada perpendicular e paralelamente ao plano de incidência, respectivamente. A primeira, segunda e terceira letras representam a polarização da luz SFG, do visível e do infravermelho, respectivamente.

\section{Atividade enzimática da LIS}

A ação antimicrobial da LIS livre em solução (3 g/L) e imobilizada sobre os filmes $\mathrm{CAB}$ ou CMCAB foi avaliada usando-se uma dispersão aquosa de Micrococcus luteus (ATCC 4698), 1,33 g/L, como substrato, a $25{ }^{\circ} \mathrm{C}$. A atividade enzimática foi medida pelo decréscimo da turbidez da dispersão $(\Delta \tau) .{ }^{22}$ Este foi determinado pela transmitância a $650 \mathrm{~nm}$, utilizando-se um espectrofotômetro Beckmann Coulter DU-600, após 1 h de contato da dispersão com a LIS pura ou com LIS imobilizada sobre os filmes de éster de celulose. $\Delta \tau$ foi calculado pela Equação 3:

$$
\Delta \tau=\left(\tau-\tau_{0} / \tau_{0}\right) \times 100
$$

onde $\tau_{0}$ é a turbidez da dispersão da bactéria antes do contato com LIS e $\tau$ é a turbidez após $1 \mathrm{~h}$ de contato com LIS. Quanto maior $\Delta \tau$, maior é a ação bactericida da LIS.

\section{RESULTADOS E DISCUSSÃO}

\section{Características dos filmes ultrafinos de CAB e CMCAB}

$\mathrm{O}$ valor médio da espessura da camada de $\mathrm{CAB}$ obtido foi de $\mathrm{d}=$ $0,52 \pm 0,02 \mathrm{~nm}$ sobre $\mathrm{Si} / \mathrm{SiO}_{2}$, o que corresponde à quantidade de material adsorvido de $\Gamma=0,63 \pm 0,03 \mathrm{mg} / \mathrm{m}^{2}$. Considerando o polímero CMCAB, o valor médio da espessura da camada de $\mathrm{CMCAB}$ foi de $\mathrm{d}=1,9 \pm 0,2$ nm sobre $\mathrm{Si} / \mathrm{SiO}_{2}$, portanto, a quantidade de $\mathrm{CMCAB}$ adsorvido sobre $\mathrm{Si} / \mathrm{SiO}_{2}$ foi de $\Gamma=2,3 \pm 0,2 \mathrm{mg} / \mathrm{m}^{2}$. Os valores médios das espessuras dos filmes de $\mathrm{CAB}$ e $\mathrm{CMCAB}$ formados sobre $\mathrm{Si} / \mathrm{SiO}_{2}$ indicam que somente o $\mathrm{CAB}$ adsorve formando uma monocamada, uma vez que a espessura média de uma monocamada homogênea de celulose ${ }^{23}$ é aproximadamente de $0,5 \mathrm{~nm}$. Experimentos de dessorção mostraram que o processo de adsorção é irreversível para o CAB e CMCAB.

O processo de adsorção é controlado pelo balanço das interações entre polímero e substrato, substrato e solvente, polímero e solvente, como descrito por Silberberg. ${ }^{24} \mathrm{~A}$ adsorção dos polissacarídeos sobre as lâminas de $\mathrm{Si} / \mathrm{SiO}_{2}$ é provavelmente dirigida por interações favoráveis entre os grupos carbonila e hidroxila dos polissacarídeos e os grupos silanol no substrato, ${ }^{25} \mathrm{o}$ que é mais intenso para o polímero $\mathrm{CMCAB}$, pois $\Gamma_{\mathrm{CMCAB}}$ foi maior que $\Gamma_{\mathrm{CAB}}$.

Imagens topográficas de AFM (Figura 2) mostram que as superfícies dos filmes de $\mathrm{CAB}$ e $\mathrm{CMCAB}$ apresentam relevo homogêneo e que os polímeros recobrem todo o substrato. Estas características são confirmadas pelos valores de rugosidade média obtidos para os filmes de $\mathrm{CAB}$ e $\mathrm{CMCAB}$ de 0,20 $\pm 0,02$ e 0,30 $\pm 0,03 \mathrm{~nm}$, respectivamente, os quais não diferem muito da rugosidade média do substrato $0,10 \pm 0,01 \mathrm{~nm}^{26,27}$

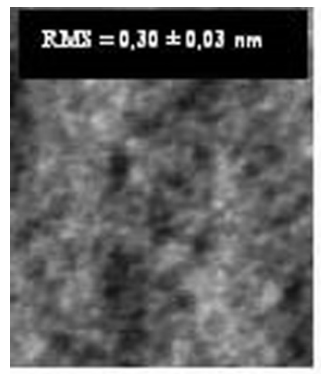

(a)

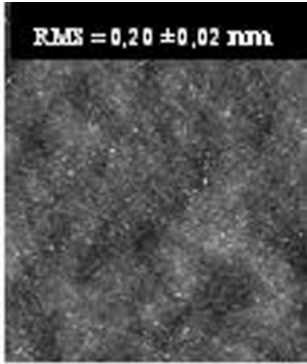

(b)

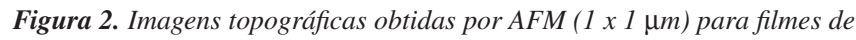
(a) $C A B, Z=4 \mathrm{~nm}, e(b) C M C A B, Z=3 \mathrm{~nm}$

Os valores dos ângulos de contato determinados para filmes de $\mathrm{CAB}$ e CMCAB $\theta_{\mathrm{a}}=54 \pm 1^{\circ}$ e $\theta_{\mathrm{a}}=60 \pm 1^{\circ}$, respectivamente, evidenciaram que a molhabilidade dessas superfícies diminuiu, pois os valores de $\theta_{\mathrm{a}}$ aumentaram em relação ao $\mathrm{SiO}_{2},{ }^{26,27} \theta_{\mathrm{a}}=5 \pm 1^{\circ}$. Portanto, a provável orientação do grupo butirato para o ar tornou as superfícies mais hidrofóbicas. Além disso, os valores relativamente baixos de $\Delta \theta$ $=9 \pm 2^{\circ}$ obtidos tanto para $\mathrm{CAB}$ como para $\mathrm{CMCAB}$ corroboraram com a homogeneidade dos filmes observada por AFM (Figura 2).

A orientação molecular preferencial de radicais alquílicos sugerida por medidas de ângulo de contato foi investigada através de medidas de SFG. Foram obtidos os espectros de SFG dos filmes de $\mathrm{CAB}$ e CMCAB em três polarizações (ssp, sps e ppp). A Figura 3 mostra os espectros de SFG obtidos a seco (interface sólido-ar) na região de 2800 a $3000 \mathrm{~cm}^{-1}$, a qual é característica de grupos metileno e metila. ${ }^{28,29}$ As bandas nos espectros obtidos na polarização ssp são mais intensas que aquelas obtidas nas polarizações sps e ppp. Além disso, os espectros na polarização ssp obtidos para CAB e CMCAB são semelhantes entre si tanto com relação à intensidade relativa das bandas como na faixa espectral em que se encontram. As bandas presentes em $2879 \mathrm{~cm}^{-1}\left(\mathrm{CH}_{3(\mathrm{~s})}\right)$ e $2942 \mathrm{~cm}^{-1}\left(\mathrm{CH}_{3(\mathrm{~F})}\right)$ são atribuídas ao estiramento simétrico do grupo metila e à ressonância de Fermi. ${ }^{28,29}$ A presença de bandas do grupo metila neste espectro mostra que as cadeias poliméricas do $\mathrm{CAB}$ e $\mathrm{CMCAB}$ se orientam preferencialmente na interface sólido-ar de modo a arranjarem os grupos $\mathrm{CH}_{3}$, em média, perpendicularmente à superfície. Além disso, 
a Figura 3 mostra que os espectros dos filmes de $\mathrm{CAB}$ e $\mathrm{CMCAB}$ nas polarizações sps e ppp são dominados por uma banda em $2970 \mathrm{~cm}^{-1}$, característica do estiramento assimétrico do grupo metila $\left(\mathrm{CH}_{3(\mathrm{as})}\right)$. Esses espectros são similares aos obtidos em filmes de Langmuir de ácidos graxos,$^{30}$ indicando que as cadeias butila se encontram em média perpendiculares à superfície dos filmes poliméricos. Portanto, com os grupos $\mathrm{CH}_{3}$ ligeiramente inclinados em relação à direção normal ao substrato. Estes resultados são coerentes com a orientação do grupo butirato para a interface sólido-ar que, consequentemente, contribui para o maior valor de ângulo de contato para os filmes de $\mathrm{CAB}$ e CMCAB em relação ao $\mathrm{Si} / \mathrm{SiO}_{2}$.
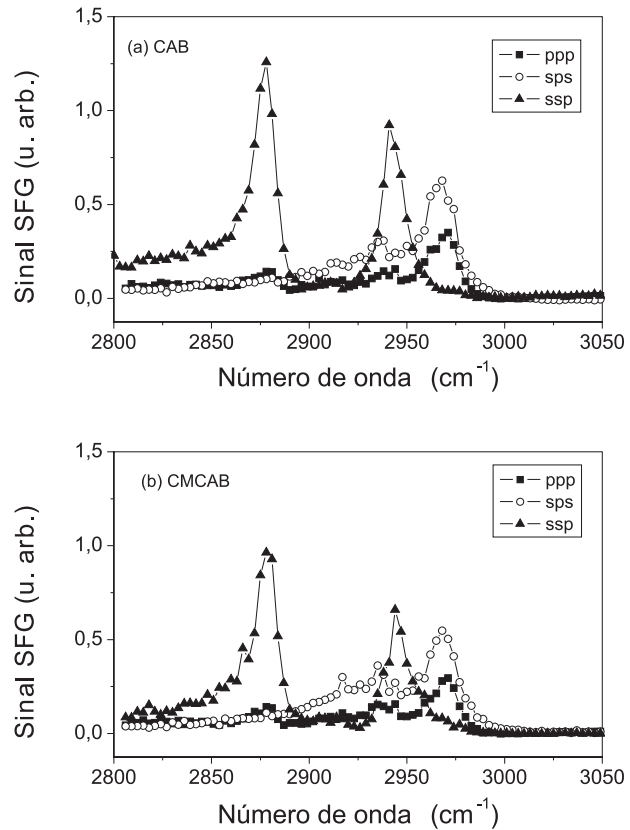

Figura 3. Espectros de SFG obtidos nas polarizações ssp, sps e ppp, no ar, para filmes de (a) CAB e (b) CMCAB depositados sobre quartzo a partir de soluções preparadas em acetato de etila

$\mathrm{O}$ espectro obtido para $\mathrm{CAB}$ e $\mathrm{CMCAB}$ na região da carbonila $\left(1600\right.$ a $\left.1800 \mathrm{~cm}^{-1}\right)$ não apresentou nenhuma banda característica do grupo, indicando que para ambos os polímeros a carbonila está randomicamente orientada na interface sólido-ar (espectro não apresentado).

\section{Adsorção de LIS ou BSA sobre filmes de CAB e CMCAB}

A Figura 4 mostra os valores médios das quantidades de LIS ou de BSA adsorvidas sobre os filmes de $\mathrm{CAB}$ e $\mathrm{CMCAB}$ adsorvidos sobre $\mathrm{Si} / \mathrm{SiO}_{2}$, em $\mathrm{pH}=6,4 \pm 0,1$, a partir de soluções aquosas ou em $\mathrm{NaCl}$, na concentração de $1,0 \mathrm{~g} / \mathrm{L}$, a $25^{\circ} \mathrm{C}$. Comparando os valores obtidos de $\Gamma_{\mathrm{LIS}}$ e $\Gamma_{\mathrm{BSA}}$, LIS e BSA adsorveram em maior quantidade sobre o filme de CMCAB do que sobre o filme de CAB. A preferencial interação entre LIS e CMCAB pode ser explicada pela presença do grupo carboximetil (CM) no CMCAB. Em meio aquoso, grupos carboximetil orientados para a interface sólido-líquido podem estar desprotonados, gerando cargas negativas na superfície. Como o ponto isoelétrico (pI) da LIS ${ }^{31}$ é 11, em pH= 6,4 $\pm 0,1$ a LIS encontra-se com carga líquida positiva, favorecendo interações eletrostáticas entre filme de CMCAB e LIS. Os valores de $\Gamma_{\text {LIS }}$ determinados para o poliânion poli(ácido acrílico), PAA, são da mesma ordem de grandeza daqueles encontrados para CMCAB ${ }^{31}$ Além disso, ocorrem interações hidrofóbicas entre resíduos hidrofóbicos de LIS e os radicais butila. Por outro lado, o pI da BSA ${ }^{32}$ é geralmente dado como uma faixa de
4,7 a 4,9. Portanto, em $\mathrm{pH}=6,4 \pm 0,1$ a BSA encontra-se com carga líquida negativa, o que poderia provocar certa repulsão eletrostática pelos grupos carboxilatos da superfície de $\mathrm{CMCAB}$ e diminuir a adsorção. Porém, a presença do grupo carboximetil (CM) no CM$\mathrm{CAB}$ provavelmente intensifica as interações do tipo dipolo-dipolo ou ligações de hidrogênio com a proteína. A adsorção de BSA sobre filmes de PAA é uma ordem de grandeza menor que aquela observada sobre $\mathrm{CAB}$ ou $\mathrm{CMCAB},{ }^{31}$ indicando que a adsorção sobre os ésteres de celulose é provavelmente dirigida por interações hidrofóbicas.
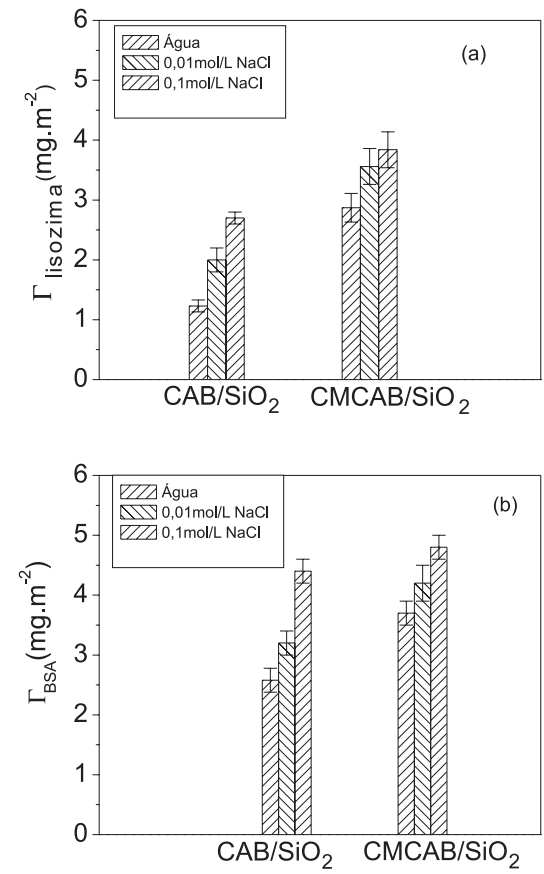

Figura 4. Valores médios da quantidade de BSA ou LIS adsorvidas ( $\Gamma)$ sobre os filmes de CAB e CMCAB depositados sobre $\mathrm{Si} / \mathrm{SiO}$, a partir de soluções $(C=1,0 \mathrm{~g} / \mathrm{L})$ preparadas em água pura, 0,01 mol/L $\mathrm{NaCl}$ e 0,10 mol/L $\mathrm{NaCl}$, a $25^{\circ} \mathrm{C}$ e $\mathrm{pH}=6,4 \pm 0,1$

O efeito da força iônica sobre a adsorção da LIS e da BSA foi investigado como mostra a Figura 4. Os valores de $\Gamma_{\mathrm{LIS}}$ e $\Gamma_{\mathrm{BSA}}$ aumentaram quando foi adicionado $\mathrm{NaCl}$ nas soluções, independentemente do substrato utilizado $\mathrm{CAB}$ ou $\mathrm{CMCAB}$. Esta tendência foi mantida quando se aumentou a força iônica do meio de 0,01 para $0,1 \mathrm{~mol} / \mathrm{L}$ de $\mathrm{NaCl}$. Este comportamento pode ser explicado pela desidratação das moléculas de LIS e de BSA, devido à solvatação de íons do sal ao redor das proteínas. ${ }^{33}$ Logo, as biomoléculas tendem a agregar em solução e provavelmente adsorvem sobre as superfícies do $\mathrm{CAB}$ e CMCAB por interações hidrofóbicas.

Para avaliar se o processo de adsorção das biomoléculas é reversível ou irreversível, todos os filmes obtidos para LIS e BSA foram deixados em contato com os seus respectivos solventes (água ou solução 0,01 ou $0,1 \mathrm{~mol} / \mathrm{L} \mathrm{de} \mathrm{NaCl}$ ). Este controle foi realizado por meio da técnica de elipsometria, avaliando se houve variação na espessura das camadas de proteína adsorvida sobre os filmes de $\mathrm{CAB}$ e CMCAB. Para todos os sistemas investigados, observou-se diminuição de $\sim 5 \%$ na espessura da camada proteica, indicando que o processo é irreversível.

A imobilização de LIS e BSA sobre os filmes de ésteres de celulose modificou a molhabilidade dos filmes de CAB e CMCAB, como pode ser visto na Tabela 2. Após a adsorção de LIS e BSA, houve um decréscimo dos ângulos de contato em relação aos filmes dos ésteres de celulose, tornando os filmes mais hidrofílicos. Provavelmente, as biomoléculas orientaram os resíduos hidrofóbicos para a superfície 
Tabela 2. Valores de ângulo de contato de avanço $\left(\theta_{\mathrm{a}}\right)$, de recesso $\left(\theta_{\mathrm{r}}\right)$ e da histerese do ângulo de contato $(\Delta \theta)$ em graus para LIS e BSA imobilizadas sobre os filmes de $\mathrm{CAB}$ e $\mathrm{CMCAB}$ em diferentes forças iônicas

Biomoléculas

\begin{tabular}{|c|c|c|c|c|c|c|c|c|c|}
\hline \multirow{3}{*}{ a } & \\
\hline & \multicolumn{3}{|c|}{ Água } & \multicolumn{3}{|c|}{$\mathrm{NaCl} 0,01 \mathrm{~mol} / \mathrm{L}$} & \multicolumn{3}{|c|}{$\mathrm{NaCl} 0,1 \mathrm{~mol} / \mathrm{L}$} \\
\hline & $\theta_{\mathrm{A}}$ & $\theta_{\mathrm{R}}$ & $\Delta \theta$ & $\theta_{\mathrm{A}}$ & $\theta_{\mathrm{R}}$ & $\Delta \theta$ & $\theta_{\mathrm{A}}$ & $\theta_{\mathrm{R}}$ & $\Delta \theta$ \\
\hline $\mathrm{CAB} / \mathrm{SiO}_{2}$ & $47 \pm 2$ & $29 \pm 1$ & $18 \pm 2$ & $49 \pm 1$ & $30 \pm 1$ & $19 \pm 1$ & $44 \pm 1$ & $25 \pm 2$ & $19 \pm 1$ \\
\hline $\mathrm{CMCAB} / \mathrm{SiO}_{2}$ & $52 \pm 1$ & $31 \pm 2$ & $21 \pm 1$ & $46 \pm 2$ & $28 \pm 1$ & $18 \pm 3$ & $51 \pm 2$ & $30 \pm 2$ & $21 \pm 3$ \\
\hline \multirow{3}{*}{ Superfícies } & \multicolumn{9}{|c|}{ BSA } \\
\hline & \multicolumn{3}{|c|}{ Água } & \multicolumn{3}{|c|}{$\mathrm{NaCl} 0,01 \mathrm{~mol} / \mathrm{L}$} & \multicolumn{3}{|c|}{$\mathrm{NaCl} 0,1 \mathrm{~mol} / \mathrm{L}$} \\
\hline & $\theta_{\mathrm{A}}$ & $\theta_{\mathrm{R}}$ & $\Delta \theta$ & $\theta_{\mathrm{A}}$ & $\theta_{\mathrm{R}}$ & $\Delta \theta$ & $\theta_{\mathrm{A}}$ & $\theta_{\mathrm{R}}$ & $\Delta \theta$ \\
\hline $\mathrm{CAB} / \mathrm{SiO}_{2}$ & $50 \pm 1$ & $40 \pm 1$ & $10 \pm 1$ & $55 \pm 1$ & $39 \pm 2$ & $16 \pm 2$ & $49 \pm 1$ & $38 \pm 2$ & $11 \pm 2$ \\
\hline $\mathrm{CMCAB} / \mathrm{SiO}_{2}$ & $51 \pm 1$ & $37 \pm 2$ & $14 \pm 2$ & $49 \pm 1$ & $33 \pm 1$ & $16 \pm 2$ & $50 \pm 1$ & $35 \pm 2$ & $15 \pm 2$ \\
\hline
\end{tabular}

dos ésteres de celulose e, consequentemente, os resíduos hidrofílicos para a interface sólido-ar. Observou-se também um aumento na histerese do ângulo de contato, indicando aumento de rugosidade e/ ou heterogeneidade química na superfície. As imagens topográficas de AFM obtidas para o filme contendo LIS adsorvida a partir do uso de uma solução de $\mathrm{NaCl}$ 0,1 $\mathrm{mol} / \mathrm{L}$ indicam a presença de estruturas cujas alturas variam de 10 a $15 \mathrm{~nm}$ sobre filmes de CAB (Figura $2 \mathrm{~S}$, material suplementar) e de 10 a $12 \mathrm{~nm}$ sobre filmes de CMCAB (Figura 2S, material suplementar). Considerando que as dimensões cristalográficas reportadas para LIS ${ }^{34}$ são $4,5 \times 3 \times 3 \mathrm{~nm}^{3}$, estas estruturas podem ser agregados de LIS, os quais causam aumento na histerese das medidas de ângulo de contato. Agregados de BSA também foram observados sobre os filmes de CAB e CMCAB (imagens não apresentadas). De forma geral, o tamanho médio dos agregados aumenta com o aumento da força iônica, devido à interação da água de hidratação da proteína com os íons em solução. ${ }^{33}$

Para se verificar possíveis mudanças conformacionais da LIS após imobilização sobre os filmes de $\mathrm{CAB}$ e $\mathrm{CMCAB}$, testes enzimáticos foram realizados utilizando dispersões de $M$. luteus como substrato. Para este estudo, foram escolhidos os filmes de LIS adsorvidos a partir de $0,1 \mathrm{~mol} / \mathrm{L}$ de $\mathrm{NaCl}$ sobre os filmes de $\mathrm{CAB}$ e CMCAB, porque foram aqueles que apresentaram maiores valores de $\Gamma_{\text {LIS }}$. A atividade enzimática de LIS livre e imobilizada foi correlacionada com o decréscimo da turbidez $\Delta \tau$ da dispersão de micro-organismo. Após $1 \mathrm{~h}$ de contato dos filmes de LIS com a dispersão, os valores de $\Delta \tau$ foram $23 \pm 1 \% \mathrm{e}$ $29 \pm 1 \%$ para LIS adsorvida sobre CAB e CMCAB, respectivamente. Para efeito de comparação LIS adsorvida sobre $\mathrm{Si} / \mathrm{SiO}_{2}$, uma superfície mais hidrofílica, apresentou $\Delta \tau 49 \pm 4 \%{ }^{35}$ e LIS livre (em quantidade equivalente à adsorvida) apresentou $\Delta \tau 100 \%$. A menor atividade sobre superfícies de éster de celulose pode ser explicada pela agregação das moléculas de LIS sobre os filmes de CAB e CMCAB (Figura 2S, material suplementar). A atividade enzimática da LIS é dependente da preservação de sua estrutura nativa, que ocorre quando as ligações de dissulfeto são mantidas intactas. ${ }^{10} \mathrm{O}$ mecanismo catalítico envolve os resíduos hidrofílicos Glu35 e Asp52, os quais se ligam ao anel glicosídico, de maneira que Glu35 é o responsável pela catálise ácida e Asp52 pela estabilização do íon carbônio. Os resíduos hidrofóbicos Trp62 e Trp63 estabilizam a estrutura aberta do sítio ativo. ${ }^{10,36,37}$ A perda parcial de atividade enzimática observada para LIS imobilizada pode ser explicada por mudança conformacional, devida à adsorção ou exposição reduzida do sítio ativo causada pela agregação.

Após os experimentos de atividade biocida, os filmes de LIS foram lavados, secos e suas espessuras foram determinadas por elipsometria, com o intuito de verificar se houve dessorção da enzima. Como não houve variação de espessura, os filmes foram reutilizados.
Após $1 \mathrm{~h}$ de contato com a dispersão, a atividade da LIS manteve-se, pois $\Delta \tau$ foi de $32 \pm 2 \%$, mostrando que mesmo após armazenagem em dessecador a $25{ }^{\circ} \mathrm{C}$ por um dia, o nível de atividade catalítica original foi mantido. Este resultado é bastante interessante porque mostra que, embora a atividade enzimática de LIS adsorvida seja mais baixa que aquela medida para LIS livre, a estrutura após adsorção e uso é mantida, permitindo reuso.

\section{CONCLUSÕES}

Filmes ultrafinos de $\mathrm{CAB}(\sim 0,5 \mathrm{~nm})$ e CMCAB $(\sim 2,0 \mathrm{~nm})$ adsorvidos sobre lâminas de $\mathrm{Si} / \mathrm{SiO}_{2}$ tendem a expor os grupos alquila para a interface sólido-ar. Esta orientação preferencial pôde ser evidenciada por espectroscopia SFG e medidas de ângulo de contato. Vale ressaltar que para estudos de filmes finos e interfaces estas duas técnicas se complementam muito bem. A primeira fornece informações microscópicas, enquanto a segunda revela propriedades macroscópicas.

Com relação à aplicação de filmes de $\mathrm{CAB}$ e CMCAB como suporte para imobilização de biomoléculas, pode-se afirmar que a presença do grupo carboximetil (CM) na estrutura química do $\mathrm{CMCAB}$, mesmo em pequena concentração $\left(\mathrm{DS}_{\mathrm{CM}}=0,33\right)$ favorece a adsorção de proteínas (BSA e LIS). No caso particular de LIS, a adsorção sobre $\mathrm{CAB}$ ou $\mathrm{CMCAB}$ induziu mudanças conformacionais que provocaram redução na atividade biocida. Entretanto, esta redução pode ser compensada pelo fato de manter a atividade biocida no reuso. Do ponto de vista prático, a imobilização de LIS sobre filmes de CAB e $\mathrm{CMCAB}$ agrega propriedades bactericidas importantes para o uso dos mesmos como revestimento de dispositivos que requerem assepsia.

\section{MATERIAL SUPLEMENTAR}

As Figuras 1S e 2S estão disponíveis em http://quimicanova.sbq. org.br na forma de arquivo PDF, com acesso livre.

\section{AGRADECIMENTOS}

À FAPESP, CNPq e CAPES (Rede Nanobiotecnologia) pelo apoio financeiro.

\section{REFERÊNCIAS}

1. Charreyre, C. M-T.; Tcherkasskaya, O.; Winnik, M. A.; Hiver, A.; Delair, T.; Cros, P.; Pichot, C.; Mandrand, B.; Langmuir 1997, 12, 3103.

2. Wiegand, G.; Jaworek, T.; Wegner, G.; Sackmann, E.; Langmuir 1997, 13,3563 . 
3. Delair, T.; Meunier, F.; Elaissari, A.; Charles, M-H.; Pichot, C.; Colloids Surf., A 1999, 153, 341.

4. Sackmann, E.; Science 1996, 271, 43.

5. Edgar, K. J.; Buchanan, C. M.; Debenham, J. S.; Rundquist, P. A.; Seiler, B. D.; Shelton, M. C.; Tindall, D.; Prog.Polym. Sci. 2001, 26, 1605.

6. Edgar, K. J.; Cellulose 2007, 14, 49.

7. Walker, K. R.; Posey-Dowty J.; Seo, K. S.; Wilson, A. K.; Surface Coatings Australia 2002, 39, 11.

8. Obie, R. T.; US PI $2004030801,2004$.

9. Bauer, R. D.; US PI $2005166794,2005$.

10. Franck, R. W.; Bioorg. Chem. 1992, $20,77$.

11. Carter, D. C.; Ho, J. X.; Adv. Protein Chem. 1994, 45, 153.

12. Gonçalves, D.; Irene, E. A.; Quim Nova 2002, 25, 794.

13. Azzam, R. M.; Bashara, N. M.; Ellipsometry and Polarized Light, North Holland: Amsterdam, 1979.

14. Palik, E. D.; Handbook of Optical Constants of Solids, Academic Press, Inc.: London, 1985.

15. Kosaka, P. M.; Kawano, Y.; El Seoud, O. A.; Petri, D. F. S.; Langmuir 2007, 23, 1216.

16. Malmsten, M.; Protein architecture: Interfacing molecular assemblies and immoblilization biotechnology, Marcel Dekker: New York, 2000.

17. Ortega-Vinuesa, J. L.; Tengvall, P.; Lundstrom, I.; Thin Solid Films 1998, 324, 257.

18. Adamson, A. W.; Physical Chemistry of Surfaces, $5^{\text {th }}$ ed., John Wiley \& Sons: Toronto, 1990.

19. Lambert, A. G.; Davies, P. B.; Neivandt, D. J.; Appl. Spectrosc. Rev. $\mathbf{2 0 0 5}, 40,103$

20. Ye, X.; Zuo, B.; Deng, M.; Hei, Y.; Ni, H.; Lu, X.; Wang, X.; J. Colloid Interface Sci. 2010, 349, 205.

21. Kristalyn, C. B.; Lu, X.; Weinman, C. J.; Ober, C. K.; Kramer, E. J.; Chen, Z.; Langmuir 2010, 26, 11337.
22. Bergmeyer, H. U.; Methods of enzymatic analysis, $3^{\text {rd }}$ ed., Weinheim, vol. 2.

23. Holmberg M.; Berg, J.; Stemme, S.; Odberg, L.; Rasmusson, J.; Claesson, P.; J. Colloid Interface Sci. 1997, 186, 369.

24. Silberberg, A.; J. Chem. Phys. 1968, 48, 2835.

25. Kosaka, P. M.; Kawano, Y.; Salvadori, M. C.; Petri, D, F. S.; Cellulose 2005, 12, 351 .

26. Petri, D. F. S.; Wenz, G.; Schunk, P.; Schimmel, T.; Langmuir 1999, 15, 4520.

27. Castro, L. B. R.; Petri, D. F. S.; J. Nanosci. Nanotechnol. 2005, 5, 2063.

28. Chen, C.; Wang, J.; Woodcook, S. E.; Chen, Z.; Langmuir 2002, 18, 1302.

29. Opdahl, A.; Koffas, T. S.; Amitay-Sadovsky, E.; Kim, J.; Somorjai, G. A.; J. Phys.: Condens. Matter 2004, 16, R659.

30. Guyot-Sionnest, P.; Hunt, J. H.; Shen, Y. R.; Phys. Rev. Lett. 1987, 59, 1597.

31. Belegrinou, S.; Mannelli, I.; Lisboa, P.; Bretagnol, F.; Valsesia, A.; Ceccone, G.; Colpo, P.; Rauscher, H.; Rossi, F. ; Langmuir 2008, 24, 7251.

32. Serefoglou, E.; Oberdisse, J.; Staikos, G.; Biomacromolecules 2007, 8, 1195.

33. Arakawa, T.; Timasheff, S. N.; Biochemistry 1984, 23, 5912.

34. Zhou, D.; Wang, X.; Birch, L.; Rayment, T.; Abell, C.; Langmuir 2003, 19,10557

35. Silva, R. A.; Urzúa, M. D.; Petri, D. F. S.; J. Colloid Interface Sci. 2009, $330,310$.

36. Blake, C. F.; Koenig, D. F.; Mair, G. A.; North, A. C. T.; Phillips, D. C.; Sarma, V. R.; Nature 1965, 206, 757.

37. Kirby, A. J.; Nature Structural Biology 2001, 8, 737. 